\title{
REFORMA TRABALHISTA E TEMPO DE TRABALHO: RECOMPOSIÇÃO DOS INSTRUMENTOS LEGAIS DO TRABALHO ASSALARIADO NO BRASIL*
}

\author{
Rosangela Nair de Carvalho Barbosa \\ Mossicléia Mendes da Silva
}

\section{Introdução}

O presente texto aborda a recente revisão da legislação trabalhista no Brasil, pela lei 13.467/2017, no Governo Michel Temer (2016-2018), compreendendo-a na onda mais geral de revisões de legislações trabalhistas no capitalismo, impulsionadas pela crise do capital iniciada nos anos de $1970 .{ }^{1}$

Com efeito, assiste-se em todos os países, ao largo dos últimos 40 anos, à acirrada recomposição do trabalho excedente, com a duração e as características do tempo de trabalho sendo expostas no olho do furacão das novas exigências da acumulação de capital. Investigando sobre isso na realidade brasileira, elaboramos a hipótese de que as novas condições de produção impulsionam a obsolescência de segmentos importantes das legislações trabalhistas, como vigoraram no curso do século XX. Isso porque o capital criou artimanhas para transformar mais frações do tempo social do trabalhador em tempo de trabalho, avançando fronteiras físicas e morais sobre o tempo destinado à saúde, à cultura, à fruição e às relações afetivas e sociais dos trabalhadores, por meio da compressão do tempo de intervalos, de descansos, de almoço, de lanche e mesmo de uso de banheiros - as porosidades do trabalho. Isso porque o limite da jornada de trabalho não é estabelecido pelas necessidades humanas, "ao contrá-

* DOI - 10.29388/978-65-86678-15-4-0-f.27-48

1 Concebemos essa reforma como uma contrarreforma nos termos gramscianos, pois rompe com a proteção progressiva dos direitos do trabalho como situa o artigo $7 \mathrm{da}$ Constituição Federal e marca um retrocesso social frente às garantias trabalhistas conquistadas, em favor do novo ciclo de dominação do capital. Acrescentamos ainda que a crise estrutural do capital aberta a partir dos anos de 1970 é uma referência importante para entender a recomposição das bases do valor por meio de expropriações sociais e isso não é possível de desenvolvermos nesse texto Cf. Barbosa (2018). 
rio, é o maior dispêndio possível diário da força de trabalho, por mais prejudicial, violento e doloroso que seja, que determina o limite do tempo de descanso do trabalhador" (MARX, 2008, p. 307).

Se o século XX abrigou lutas operárias com importantes conquistas jurídicas de reconhecimento da jornada de 8 horas diárias, de férias, de descanso semanal e outras liberações remuneradas do trabalho, para a maior parte do mundo ocidental, a transição para o século XXI foi também de generalização da captura de tempo livre, intensificando e prolongando o tempo de trabalho. Isso é especial porque o capital, depois da Segunda Guerra Mundial, de um lado, se apropriou do tempo livre colocando-o a serviço dos negócios, através do consumo de objetos concretos e serviços de lazer e de turismo para os descansos e férias; de outro lado, aprofundou as desigualdades e as hierarquias de formas contratuais de trabalho no mundo. A crise do ciclo expansionista, nos anos de 1970, impulsiona uma nova recomposição da desmedida do capital sobre o tempo de vida dos trabalhadores e o regime híbrido de acumulação (fordista e toyotista) com intensificação e prolongamento do tempo de trabalho apropriado pelo capital.

Esse quadro de determinações históricas baliza nossa interpretação da atual legislação do trabalho no Brasil e para melhor expô-la dividimos o texto em três seções. A primeira, situa as referências marxianas sobre a categoria tempo de trabalho no âmbito da forma social capitalista. A segunda, esclarece elementos da configuração atual do trabalho no tocante ao prolongamento e a intensidade do trabalho. E, por último, esses pressupostos auxiliam a problematização dos traços da nova legislação trabalhista que altera substancialmente o emprego, insistindo que a regulação social do trabalho capitalista e a sua gestão respondem historicamente às condições estruturais de produção do valor e sua reforma constitui um novo estágio de apropriação de trabalho excedente.

\section{O tempo de trabalho e a sanha do capital por excedente}

A crítica da forma social que empurra os indivíduos para o trabalho e faz dele a principal atividade no tempo social faz Marx entender que, como proprietários privados, os indivíduos aparecem na mística burguesa como independentes, agregados fenomenicamente como indivíduos que buscam seus interesses, mas o elo social entre eles decorre da dependência mútua, da permuta dos indivíduos independentes, para atenderem às suas necessidades sociais. Ainda que aparentemente independentes uns dos outros, os indivíduos estão 
conectados socialmente pelo intercâmbio de mercadorias; inclusive, a força de trabalho que, como mercadoria, tem seu valor útil (capacidade de trabalho), trocado por dinheiro para compra de meios de vida.

Os fundamentos marxianos especificam que, como toda mercadoria, a força de trabalho é comprada e vendida pelo seu valor e o mesmo é medido pelo tempo de trabalho necessário para produzi-la, ou seja, o tempo de trabalho contido nos itens de subsistência, socialmente determinados. A jornada de trabalho é composta por esse tempo de trabalho necessário, mais o tempo restante apropriado pelo capital, decorrendo daí a taxa de mais-valor que flui do valor excedente criado. Com efeito, de um lado, aumento de valor, de outro, dispêndio de força de trabalho a mais. Trata-se de uma relação de troca de mercadorias sui generis porque o valor da força de trabalho é subconsiderado, na medida em que seu pagamento é referenciado em parte da jornada (trabalho necessário) e não na magnitude produzida no conjunto do tempo de trabalho vendido. ${ }^{2}$ Esta é a face oculta da legislação que regula o trabalho capitalista, em qualquer época.

A dupla dimensão do trabalho capitalista viabiliza a generalização da troca de mercadorias por conta do trabalho em geral (comum) contido em cada uma, abstraídas aquelas qualidades específicas laborais de tecelão ou marceneiro (os trabalhos concretos). Essa igualação dos trabalhos que viabiliza a troca é revelada como dispêndio de força de trabalho humana, que é a dimensão comum de todos os trabalhos - diferenciando-se apenas em quantidade (proporção) de tempo de trabalho. Não qualquer tempo, mas o tempo socialmente necessário. Ou seja, a grandeza de valor da mercadoria determinada pelo tempo de trabalho para produzir a mercadoria, em condições sociais médias de produtividade, no tocante ao alcance educacional, tecnológico e cultural de dada época, mundialmente referenciadas e sob pena da transferência de mais-valor aos capitais concorrentes.

Inclusive, sublinha Marx, que o dispêndio de energia de trabalho como medida de valor é uma especificidade do capitalismo porque, para isso, é necessário a propriedade privada como estrutura do modo de produção, em razão do

2 Ainda que o trabalho excedente tenha existência em outras formas sociais, a peculiaridade no capitalismo merece nossa atenção, afinal no trabalho do camponês feudal, por exemplo, a dimensão excedente era perceptível e palpável, pois aquele executava o trabalho necessário à reprodução no território de moradia. No capitalismo, o trabalho a mais não é distinguível pelos trabalhadores o que garante a reprodução desse esquema social de usurpação num contexto produtivo voltado para a troca, independente da cobertura das necessidades sociais. Por isso, o tempo de trabalho é chave na produção e reprodução ampliada do valor. 
sobretrabalho capturado dos destituídos de modos de vida. Se o gasto do capital com a força de trabalho é reposto, então ele é simples processo de produzir valor, "Ultrapassando esse ponto, o processo de produzir valor torna-se processo de produzir mais-valor (valor excedente)" (MARX, 2008, p. 228), ou seja, o processo de valorização do valor ocorre por meio do trabalho excedente, não pago.

Abstraídas as especificidades de cada trabalho concreto restam nos produtos do trabalho "a mesma objetividade impalpável, a massa pura e simples do trabalho humano em geral, do dispêndio de força de trabalho humano" (MARX, 2008, p.60). ${ }^{3}$ Os trabalhos concretos são formas diferentes de dispender força de trabalho humana e essas especificidades úteis, oriundas dos trabalhos concretos variados, são abstraídas, operando-se a redução à condição social comum como energia humana (força física e neural) cristalizada em dado tempo. "Uma abstração que se realiza todos os dias no processo de produção social” (MARX, 1977, p.18), longe, portanto, de uma redução subjetiva (meramente mental), externa ao mundo real. ${ }^{4} \mathrm{O}$ trabalho abstrato é substância real que se opõe dialeticamente ao trabalho concreto, pois subordina e controla o trabalho privado, como trabalho alienado. ${ }^{5}$ No entanto, o trabalho abstrato não decorre da contabilidade sobre trabalhos individuais e sim da consideração à média social do trabalho coletivo, cooperado. Para Marx é suficiente que sejam trabalhos subordinados em cooperação, sem menção a cada membro particular: "Se se considerar o trabalhador coletivo constituído pela oficina, a sua atividade

3 "A indiferença para com o trabalho determinado corresponde a uma forma de sociedade na qual os indivíduos podem, com facilidade, transferir-se de um trabalho para outro, e onde o tipo determinado de trabalho é para eles algo casual e, portanto, indiferente. O trabalho aqui não só na categoria, mas na realidade, não é mais do que um meio para a criação de riqueza em geral e deixou de estar organicamente ligado com o indivíduo numa particularidade, como determinação.” (MARX, 2011. pp.5758).

4 O valor tem existência real por resultar "de um fazer - produzir para troca e trocar adquirindo o caráter de coisas social que, conforme a formulação do fetichismo, retira dos produtores privados a condição de sujeitos controladores do processo no qual tomam parte e faz com que eles sejam controlados pelo processo. [...] o trabalho abstrato [...] é também uma substância, algo real que se opõe a eles, pois sua realidade é a de um processo que os subordina e controla" (GRESPAN, 2012, p.55).

5 A formulação de Grespan a esse respeito é acertada: "No tipo de sociedade em que os trabalhos concretos são imediatamente trabalhos privados dos produtores autonomizados, a troca de mercadorias representa simultaneamente o oposto do caráter privado e do concreto, ou seja, ela é instância de socialização apenas na medida em que realiza a abstração do concreto dos trabalhos privados” (2012, p.53), portanto uma socialização de indivíduos alienados. 
combinada realiza-se materialmente e de maneira direta num produto total [...] e aqui é absolutamente indiferente (que) a função deste ou daquele trabalhador coletivo" (MARX, s/d, p. 110), porque é mero elo do trabalho combinado, onde a média do valor é a média social mundial do capital total, dentro do quadro do desenvolvimento histórico capitalista.

Essa condição social imprime concretude ao valor como expressão do produzir para a troca como uma coisa social, onde os produtores privados não são sujeitos do processo (MARX, 2011). Ao contrário, a lei do valor os subordina e os controla (inclusive na sua condição de trabalhadores concretos), como totalidade na esfera do labor e do modo de vida em geral, como reprodução social coisificada.

Por isso, a jornada de trabalho precisa ser pensada no movimento imanente da dinâmica de autovalorização do capital que se volta até mesmo para espiar, beliscar e mordiscar o tempo das refeições dos trabalhadores, afinal átomos do tempo formam o lucro. Isso equivale a dizer que qualquer prolongamento da jornada encurtando intervalos, pode levar, por exemplo, à captura do mínimo de 5 minutos ao dia, elevando a jornada anual de 12 para 13 meses, ampliando o trabalho excedente.

De outro lado, é preciso pensar que a compulsão pela expansão escalar de capital permanentemente impulsiona a aceleração técnica, com aumento e inovação continuada (trabalho morto) - tendo por sujeito o processo que envolve a equação D-M-D' e não mais a mera aquisição de coisas úteis M-D-M da circulação simples. Daí uma estrutura social que galvaniza a transformação permanente das forças produtivas para aumentar a produtividade como oportunidade de capturar mais trabalho excedente. Contraditoriamente, se coloca em movimento a desmedida do capital pela absorção de força de trabalho (trabalho vivo), com o prolongamento das jornadas e a intensificação das mesmas, com lentos processos de privação do sono, de descanso e de convivência social dos trabalhadores, em favor da entrega de maior tempo social de vida para o trabalho do capital.

A obstinação pela expansão do valor torna a modernização permanente das forças produtivas o meio estratégico de reprodução ampliada do capital, alimentando a concorrência pela elevação tecnológica e a disputa de capitais. ${ }^{6}$ Ao mesmo tempo, esses condicionamentos exigem potentes investimentos de capital constante (maquinário e tecnologia) e provocam a progressiva queda do va-

${ }^{6}$ E, para essa dinâmica econômica, se estruturam políticas internas de concentração e centralização de capitais, assim como dinâmicas mundiais, como abordou Marx, em especial, no capítulo 23 do livro I e no livro III de O Capital. 
lor das mercadorias, instigada pela concorrência de capitais, permitindo a massificação do consumo com o impulsionamento de novas necessidades sociais mercadorizadas. A queda do preço dos produtos e o consumo em massa foram resultados efetivos da grande indústria no capitalismo tardio como mostra Mandel (1982) e a forma capitalista dessa generalização da mercadoria conectou os indivíduos sem meios de trabalho, ao passo que transformou progressivamente seus meios de vida em objeto de valorização, universalizando o intercâmbio capitalista e, portanto, a sanha por mais tempo de trabalho, diminuindo o tempo livre.

A necessidade de incorporar esses pressupostos à análise da reforma trabalhista é primordial e pode nos desviar de uma percepção meramente politicista da regulação do trabalho nos governos dos últimos anos, ainda que a política seja importante desde que tratada no contexto das exigências da valorização do valor que especifica e vertebra a totalidade da forma social capitalista. Vejamos.

\section{Tempo de trabalho avança sobre o tempo de vida}

A breve exposição desenvolvida até aqui é fundamental para entendermos que, em termos normativos, a lei 13.467/2017 expressa uma específica forma social de tempo de trabalho e podemos apreendê-la na realidade em três dimensões: duração, distribuição e intensidade. A duração é representada na jornada de trabalho legalmente instituída para os contratos de emprego. A distribuição no modo como a jornada pode ser executada, revelando maior ou menor flexibilidade, para contabilização no dia, no mês, no ano. "Assim, temos a anualização, a modulação (ou chamado banco de horas), a ampliação do tempo de trabalho em horários e dias atípicos, como finais de semana ou à noite, bem como uma maior demanda por hora-extra e sobreaviso." (CARDOSO, 2013, p. 355). A intensidade do trabalho é mais obscura e está relacionada à carga geral de trabalho (dispêndio de energia física, mental e emocional) por unidade de tempo, observando-se "a tarefa, o posto de trabalho, o ambiente físico, os objetos a manipular, a postura, as relações entre os trabalhadores, destes com a chefia ou com os usuários, o grau de autonomia, enfim, todo o ambiente de trabalho" (CARDOSO, 2013, p.358). ${ }^{7}$

\footnotetext{
7 Isso deve ser associado ao conhecimento sobre o perfil social da força de trabalho, seus anseios e o contexto histórico das relações de trabalho.
} 
Mesmo dentro dessa complexidade empírica que envolve o tempo de trabalho, a lei da reforma trabalhista brasileira recente, ainda que não altere a duração da jornada de trabalho - permanecendo o instituído na Constituição Federal de 1988 ou de outras legislações específicas de categorias profissionais-, avança sobre a flexibilização da distribuição e sobre a intensidade do tempo de trabalho, como abordaremos mais à frente.

Em termos de tendência histórica, os estudos de Antunes (2018), Basso (2018) e Dal Rosso $(2013,2017)$ mostram que o tempo de trabalho capitalista, nos últimos anos, tendencialmente, avança e condiciona todo o tempo de vida dos trabalhadores, com o prolongamento e a intensificação da jornada de trabalho pela gestão de inspiração toyotista.

No entanto, mesmo antes, no ápice do Estado social do pós-Segunda Guerra Mundial, o tempo de trabalho extrapolou a jornada de trabalho, além da inovação tecnológica ter intensificado a produção por trabalhador/hora. Mandel (1982) mostra, por exemplo, que o esforço de guerra, os aparatos nazistas e os avanços tecnológicos foram decisivos para captura de mais tempo de trabalho excedente com larga expressão nos ganhos de produtividade entre 1950 e 1970. Basso (2018) confirma isso descrevendo que no fim desse ciclo expansionista nos EUA (1970), por exemplo, os trabalhadores já produziam mais em seis meses do que faziam em um ano do início do ciclo (1948) e, mesmo assim, "nenhuma parcela dessa elevação da produtividade se traduziu em uma diminuição da jornada de trabalho. Ao contrário, [...] um crescimento médio de 158 horas em sua jornada de trabalho anual" (BASSO, 2018, p. 48).

Com dispositivos diferentes, outro ciclo de captura de tempo de vida dos trabalhadores é aberto a partir dos anos de 1980, quando ganha terreno as primeiras experiências de revisões das normativas do trabalho nos países cêntricos (Europa, EUA e Japão), que provocaram mais uma etapa histórica de aprofundamento da intensidade do trabalho e da variabilidade das jornadas. "No Ocidente, [...], o tempo médio de trabalho dos assalariados se torna cada vez mais intensivo, acelerado, flexível e prolongado. Tanto na indústria e na agricultura, quanto [...] no mundo dos "serviços"”. (BASSO, 2018, p. 27).

Os estudos para medir a intensidade do trabalho carecem de aperfeiçoamento metodológico, inclusive, porque as estatísticas oficiais não apuram propriamente isso. Para Basso (2018), Cardoso (2013) e Dal Rosso (2013, 2017) seria importante analisar as horas de trabalho (diária, semanal, mensal e anual); o tempo de férias; as horas extras; o tempo de descanso durante a jornada; os dias de descanso nos finais de semana; e o prolongamento da vida ativa do trabalhador com o retardamento da aposentadoria. São novas formas de surrupiar o 
tempo de vida que emergem do quadro de generalizada deterioração dos salários, de jornadas elevadas e insegurança social decorrente da reestruturação empresarial, do incremento da imigração mundial e da erosão dos benefícios sociais contratuais e estatais da neoliberalização. Essa orquestrada precarização do trabalho auxilia a fragilização da resistência sindical e disciplina os trabalhadores para as novas condições do valor (ANTUNES, 2018), reiterando a pauta contra tendencial à queda da taxa de lucros (MARX, 2008).

O coração da reforma trabalhista brasileira é a exigência de competitividade capitalista por diminuição do tempo de trabalho pago e não trabalhado, assim como por flexibilização das formas de contrato e de jornadas de trabalho como abordaremos na próxima seção. As reformas trabalhistas no mundo, entre outras medidas, visam retirar a responsabilidade da empresa com os poros no trabalho, quer dizer o tempo para vestir, para deslocamento de casa, para os cuidados com familiares, para as pausas variadas, até o tempo que, para o capital, é tempo ocioso, mesmo decorrendo do descenso de demanda produtiva na empresa (BASSO, 2018). Trata-se do movimento de diminuir os tempos pagos não usados diretamente no labor e isso significa disputa também pela extinção ou diminuição de tempos pagos sem que os trabalhadores estejam no trabalho por diferentes motivos (doença, férias, estudos, maternidade). Reverter às regulações anteriormente conquistadas pelas lutas sindicais, que garantiam tempos remunerados fora do lócus produtivo, conforma a neoliberalização do modo de vida e de trabalho da agenda do capital mundialmente (KREIN et al., 2019). Isso significa encurtamento do tempo de trabalho necessário (salário) e maior disponibilidade de trabalho excedente, assim como captura de mais tempo social do trabalhador.

\section{A reforma trabalhista brasileira e o tempo de trabalho}

No âmbito da formação social brasileira - historicamente determinada pela heterogeneidade estrutural do mercado de trabalho e pela inconclusão do padrão jurídico de assalariamento - a Lei 13.467/2017 opera uma profunda e radical transformação da legislação trabalhista brasileira, alterando 201 pontos da Consolidação das Leis do Trabalho (CLT) de 1943. A espinha dorsal da CLT girava em torno do regime contratual de tempo indeterminado e com a Constituição Federal de 1988 (CF/88) os direitos trabalhistas ganharam densidade e força de cláusula pétrea, inserindo dispositivos para garantia de proteção ao tra- 
balhador em especial o direito ao trabalho, a diminuição da jornada de trabalho para 44 horas semanais e o direito à greve.

A lei 13.467/2017 consolida um novo padrão de gestão da força de trabalho na competição capitalista, no entanto, ela não é a primeira a promover alterações no sistema de regulação das relações de trabalho no Brasil. De acordo com o levantamento da pesquisa houve alterações significativas desde a promulgação da CF/1988, entre as quais destacamos a autorização para inexistência de vínculo empregatício entre cooperativa e seus associados (Lei n. 8.949/94); introdução do contrato de trabalho assalariado especial para micro e pequenas empresas (CLT-Simples); contratação por prazo determinado ${ }^{8}$ e instituição do banco de horas (Lei n. 9.601/98); ${ }^{9}$ contratação por jornada parcial (Medidas Provisórias 1709/1998 e 2164-41/2001); autorização para demissão por excesso de pessoal no serviço público (Lei 9801/1999); e a Lei n. $10.101 / 2000$, que regula a participação dos trabalhadores nos lucros e resultados da empresa. Vale ressaltar, também, a Súmula do Tribunal Superior do Trabalho (TST) 331/1993, que passou a permitir a contratação de trabalho terceirizado, em quaisquer serviços intermediários (atividades-meio), com responsabilidade subsidiária das empresas tomadoras desses serviços (PASSOS; LUPATINI, 2020). Esses dispositivos legais constituíram os instrumentos da primeira fase neoliberal no Brasil, marcado por dura ação no tocante à abertura comercial internacionalizada, privatizações das empresas públicas, achaque à seguridade social e ao movimento sindical.

Nos anos 2000, já sob os governos petistas, algumas alterações em termos de regressão de direitos trabalhistas também foram efetivadas, conforme mostra o quadro 1 abaixo.

8 A lei 9.601/1998 institui de modo generalizado o contrato por prazo determinado, aprovado em resolução de acordo coletivo. Até então só era possível contrato de trabalho temporário para atividades empresariais de caráter transitório e no caso de contratos de experiência. Com a lei, as indenizações por dispensa sem justa causa foram eliminadas desse tipo de contrato e o excesso de horas trabalhadas era compensado através de folgas, em período definido pelo empregador.

9 O Banco de Horas representou um importante dispositivo de alargamento não oficial da jornada, substituindo o pagamento das horas extras por dias de folga a critério do empregador. 
Quadro 1. Principais alterações na Regulamentação Trabalhista, na primeira década dos anos 2000

\begin{tabular}{|l|l||}
\hline $\begin{array}{l}\text { Instrumento } \\
\text { Legal Criado }\end{array}$ & Disposição \\
\hline \hline Lei 11.196/2005 & $\begin{array}{l}\text { Permissão para contratação de trabalho por meio de } \\
\text { pessoa jurídica unipessoal (CNPJ), prestadora de ser- } \\
\text { viços intelectuais, sem configuração de vínculo de } \\
\text { emprego entre a prestadora e a tomadora dos serviços } \\
\text { (a chamada "pejotização"). }\end{array}$ \\
\hline Lei 11.442/2007 & $\begin{array}{l}\text { Permissão para contratação de trabalho por meio de } \\
\text { pessoa jurídica unipessoal, prestadora de serviços de } \\
\text { transporte rodoviário de cargas, sem configuração de } \\
\text { vínculo de emprego entre a prestadora e a tomadora } \\
\text { dos serviços. }\end{array}$ \\
\hline Lei 11.718/2008 & $\begin{array}{l}\text { Permissão para contratação de trabalhador rural por } \\
\text { prazo reduzido, sem anotação da carteira de trabalho. }\end{array}$ \\
\hline $\begin{array}{l}\text { Lei Complementar } \\
128 / 2008\end{array}$ & $\begin{array}{l}\text { Cria a figura do microempreendedor individual (MEI) } \\
\text { representado por trabalhador informal com rendi- } \\
\text { mentos até R\$81.000,00 (outra versão da "pejotiza- } \\
\text { ção") }\end{array}$ \\
\hline \hline Lei 11.603/2007 & $\begin{array}{l}\text { Autorização para o trabalho aos domingos e feriados } \\
\text { no comércio em geral, desde que em consonância } \\
\text { com a convenção coletiva/acordo coletivo existente e } \\
\text { com as normas do governo municipal. }\end{array}$ \\
\hline
\end{tabular}

Fonte: elaborado pela pesquisa a partir de Campos (2015).

Esses dispositivos instrumentalizam a flexibilização da regulação do trabalho na forma emprego, no contexto da segunda fase neoliberal no país, especialmente no quadro do governo Luiz Inácio Lula da Silva (2003-2011). Já no contexto de endurecimento neoliberal e intensificação da austeridade fiscal do segundo governo Dilma Rousseff, em 2015, sancionou-se a lei 13.134, que alterou as regras de acesso a benefícios trabalhistas e previdenciários como segurodesemprego, auxílio-doença, pensão por morte e abono salarial, tornando-as 
mais rígidas e limitadoras sob o argumento dos problemas fiscais da conjuntura a despeito da restrição de direitos. ${ }^{10}$ Além disso, o governo almejava propor mudanças flexibilizadoras que valorizassem a livre negociação entre trabalhadores e empregadores a respeito das regras trabalhistas, desde que respeitada a Constituição e as convenções da Organização Internacional do Trabalho. Essa proposição do governo reeleito de Dilma Rousseff não foi à frente por pressão de lideranças sindicais e dos rumos políticos do afastamento político-jurídico da presidente. ${ }^{11}$

A terceira fase neoliberal abre uma ofensiva mais contundente sobre a legislação trabalhista, por meio do governo de Michel Temer (2017/2018), tendo em vista a abrangência e amplitude do rol de alterações e no fato de corporificar várias iniciativas já existentes e legislações dispersas em uma única lei, provocando mudanças substanciais na forma de regular as variadas relações de trabalho e jornadas flexíveis. Acreditamos que o contexto social tem sido favorável a isso por conta: a) do forte aquecimento do exército industrial de reserva mundial; b) das novas incorporações tecnológicas exterminadoras de postos de trabalho, portanto da diminuição de trabalho vivo e da elevação do desemprego estrutural; c) da heterogeneidade e da dispersão da experiência proletária; d) e do enfraquecimento da luta sindical (ANTUNES, 2018).

Aquelas mudanças da primeira e segunda fase neoliberal e as mais profundas alterações da Lei 13.467/2017 tornam legais práticas empresariais que historicamente eram realizadas à margem da lei no cotidiano de trabalho, nos

${ }^{10}$ A lei alterou o seguro-desemprego exigindo que o trabalhador tenha no mínimo 12 meses de atividade laboral (no período dos últimos 18 meses). Anteriormente eram seis meses de trabalho. A lei 13.134 estabelece que a solicitação do seguro pela segunda vez só pode ser feita por trabalhadores que estiveram empregados em no mínimo 9 meses nos últimos doze meses e de seis meses na terceira requisição. Essas requisições restringem o direito dos trabalhadores exatamente num período de arrefecimento do desemprego e das consequências do episódio da crise das hipotecas norte-americanas (2008).

${ }^{11}$ O processo jurídico-parlamentar de impeachment de Dilma Rousseff em 2016, como se sabe, do ponto de vista fenomênico, foi aberto em dezembro de 2015 e concluído em agosto de 2016, pela Câmara dos Deputados e pelo Senado, justificado como julgamento de desrespeito à lei orçamentária e à lei de improbidade administrativa. $\mathrm{O}$ baixo crescimento econômico decorrente das consequências da crise das hipotecas iniciada nos EUA (2008) e propagada no mundo, ainda influencia a economia interna do país e as medidas do Governo Dilma não conseguiram estancar a sangria. Por isso, a pressão do capital sobre o bloco político redundou nesse artifício do impeachment, um processo que suspende fundamentos constitucionais de soberania do sufrágio, ainda que tenha sido aprovado pelas instituições políticas e jurídicas da República. 
mais diversos ramos econômicos (KREIN et al., 2019). Essa institucionalização possibilita e induz a generalização das práticas de contratos e jornadas de trabalho atípicos, para instrumentalização da competitividade do capital, tendo em conta as condições mundiais do trabalho social médio.

Para isso, é operada a reconceituação do direito do trabalho, esvaziando as instituições públicas do trabalho que vigoravam no Estado capitalista dos últimos setenta anos, descentrando a definição das relações de trabalho para o âmbito da empresa, e provocando o esvaziamento da Justiça do Trabalho e da “organização sindical dos trabalhadores entendida como classe, pois tende a predominar uma organização mais descentralizada e articulada com os interesses da empresa (KREIN, 2018, p. 78). ${ }^{12}$ Ao fragmentar a experiência laborativa, a reforma aprofunda os limites da organização sindical e isso porque também institui a prevalência do negociado sobre o legislado, isto é, à despeito de quaisquer determinações legais, as negociações entre empregadores e trabalhadores seriam sempre a opção mais interessante.

Outros eixos temáticos estão nas 201 alterações realizadas na CLT pela Lei 13.467/2017, que incidem sobre as relações de trabalho, no tocante centralmente à flexibilidade nas modalidades de contratação, a despadronização da jornada e a remuneração variável (KREIN et al., 2019). ${ }^{13}$

O que está em jogo nas mudanças não é a extensão da jornada de trabalho geral, mas algo mais sofisticado como a flexibilização da lei para abrir possibilidades de variadas jornadas na empresa e na trajetória de cada trabalhador, seja ampliando as horas de acordo com a demanda, seja diminuindo-as. Dal Rosso (2018) mostra que essa flexibilidade tem ampliado a variabilidade das horas de trabalho para baixo e para além das oito horas diárias. Para Gibb (2017), essa despadronização da jornada de trabalho permite um controle mais sofisticado e eficaz do tempo de trabalho e de vida dos trabalhadores, portanto servindo como dispositivo de disciplina dos trabalhadores. Um controle possibilitado em grande medida pelos dispositivos das tecnologias de comunicação,

\footnotetext{
${ }^{12}$ Dentre outras medidas, a nova legislação atinge o financiamento dos sindicatos ao dar fim à controversa contribuição sindical obrigatória e ao diminuir as ações coletivas em favor do negociado empresa-trabalhador, isentando a participação dos sindicatos na homologação de demissões, retirando a presença de sindicato na comissão por local de trabalho e promovendo a insegurança laborativa do dirigente sindical. Ver a respeito, na lei, os artigos 444, 545, 578, 579, 582, 583, 587, 602, 611, 620.

${ }^{13}$ Outros aspectos das condições de trabalho, inclusive com incidência sobre a saúde do trabalhador não serão aqui tratados em razão da disponibilidade de espaço.
} 
que oportunizam controle da maior variabilidade e individualização da extensificação da jornada de trabalho.

Lins e Silva (2019) fundamentam também que as alterações buscam desempenhar uma dupla função: tempos de não trabalho são transformados em tempos laborais, ao passo que o limite entre um e outro se torna cada vez mais nebuloso; por ouro lado, tempos de trabalho não são reconhecidos como tais, ocasionando o descomprometimento da empresa com a remuneração e também com a saúde e segurança do trabalho (CARDOSO, 2013). Como atestam as informações sistematizadas em seguida (quadro 2), as alterações na CLT subsidiam o crescimento exponencial do trabalho extraordinário, sem remuneração para os mais diversos tipos de extrapolação da jornada; o aumento do labor intensivo na vida do trabalhador; e a adoção do contrato de trabalho com probabilidade de remuneração "zero", centrado basicamente no chamado trabalho intermitente (COUTINHO, 2017).

O leque amplo de incisões nos aspectos relativos ao tempo de trabalho reforça a pista teórica que temos perseguido e sendo o tempo de trabalho a medida histórica da riqueza social no capitalismo, é justamente sobre ele, direta ou indiretamente, que as ofensivas de flexibilização e acirramento da exploração vêm incidindo tanto no trabalho necessário quanto no trabalho excedente, o trabalho social em que se articulam os diferentes ramos econômicos.

O fim das horas it itinere - o tempo de mobilidade para locais com acesso restrito e/ou sem transporte público -, por exemplo, é parte desse estratagema de redução de custos com tempos não trabalhados, ainda que essenciais para viabilizar a produção. Antes da reforma, era pago o tempo à disposição do empregador gasto em transporte fornecido pelo próprio empregador para o local de trabalho, quando este não é atendido pelo transporte público ou a empresa situa-se em local de difícil acesso.

Por outro lado, a despadronização de turnos de trabalho autorizada pela lei desorganiza a vida social do trabalhador, confronta os horários de desenvolvimento biológico e de sociabilidade familiar, além de descaracterizar os dias de descanso remunerado. A jornada por turnos (12 horas de trabalho por 36 horas de descanso) é uma forte expressão disso, na medida em que não há remuneração de descanso semanal ou feriado, nem mesmo liberação do trabalho aos domingos.

As férias também foram atingidas por meio da autorização para parcelamento em até três vezes, demonstrando o nível de espoliação inelutável, que não considera a necessidade de recomposição física e psicológica dos trabalhadores. É claro que para o capital o trabalhador é força de trabalho, potência 
para criar valor e mais-valor, sendo o descanso através de férias um entrave à autovalorização por constituir tempo morto e por fazer parte do cálculo do tempo de trabalho necessário - a parte relativa à recomposição do trabalhador (salário).

Quadro 2. Principais alterações da CLT pela Lei 13.467/2017 (ênfase no tempo de trabalho)

\begin{tabular}{|c|c|}
\hline $\begin{array}{l}\text { Dispositivo da } \\
\text { CLT }\end{array}$ & Alteração \\
\hline art. 4- $\S 2$ & $\begin{array}{l}\text { Estabelece a não consideração do tempo em que o traba- } \\
\text { lhador permanecer nas dependências da empresa empre- } \\
\text { gadora sem estar trabalhando efetivamente para a empre- } \\
\text { sa. }\end{array}$ \\
\hline art. 58- $\S 2$ & $\begin{array}{l}\text { As horas in itinere não serão computadas na jornada de } \\
\text { trabalho }\end{array}$ \\
\hline $\begin{array}{l}\text { art. 58-A, art. 58- } \\
\S 4\end{array}$ & $\begin{array}{l}\text { Trabalho em regime de tempo parcial pode ser realizado } \\
\text { até trinta horas (ampliando o previsto antes) ou com } 26 \\
\text { horas, neste caso, podendo ascender até mais } 6 \text { horas su- } \\
\text { plementares na semana. }\end{array}$ \\
\hline art. $58-\S 5$ & $\begin{array}{l}\text { Amplia a compensação da jornada extraordinária do ban- } \\
\text { co de horas para seis meses }\end{array}$ \\
\hline art. 59 & $\begin{array}{l}\text { Autoriza a contratação de horas extras diárias (até e ho- } \\
\text { ras) por meio de contratação de horas extras por acordo } \\
\text { individual de trabalho, por convenção ou acordo coleti- } \\
\text { vo. }\end{array}$ \\
\hline $\operatorname{art.59-~§5~}$ & $\begin{array}{l}\text { Expansão do banco de horas, de compensação de horas } \\
\text { extraordinárias, para também autorizá-lo por acordo indi- } \\
\text { vidual de trabalho }\end{array}$ \\
\hline art. $59-\S 6$ & $\begin{array}{l}\text { Estabelece compensação de jornada por acordo individu- } \\
\text { al, tácito ou escrito }\end{array}$ \\
\hline $\begin{array}{l}\text { art. 59-A; § úni- } \\
\text { co do art. 59-A }\end{array}$ & $\begin{array}{l}\text { Institui a jornada de } 12 \mathrm{~h} \text { x } 36 \mathrm{~h} \text { (doze horas de trabalho } \\
\text { por trinta e seis horas de descanso), mediante acordo in- } \\
\text { dividual de trabalho, sem descanso semanal remunerado } \\
\text { ou gozo de feriado e com simples indenização do inter- } \\
\text { valo intrajornada; }\end{array}$ \\
\hline art.61- $\S 1$ & $\begin{array}{l}\text { Estabelece que o tempo que extrapola a jornada contra- } \\
\text { tual pode ser exigido independentemente de previsão em }\end{array}$ \\
\hline
\end{tabular}




\begin{tabular}{||l|l||}
\hline & norma coletiva \\
\hline art. 62-III & $\begin{array}{l}\text { Define que os empregados do teletrabalho não fazem jus } \\
\text { ao recebimento de horas extras }\end{array}$ \\
\hline art.71- §4 & $\begin{array}{l}\text { Institui que os intervalos da intrajornada podem ser inde- } \\
\text { nizados pelo valor do período suprimido, estimulando } \\
\text { estímulo à não concessão de intervalos }\end{array}$ \\
\hline art.75- B & $\begin{array}{l}\text { No regime de teletrabalho mesmo o trabalhador compa- } \\
\text { recendo regularmente à empresa, não descaracteriza a } \\
\text { forma de trabalho realizada fora das dependências do } \\
\text { empregador, portanto, sem direito à percepção de horas } \\
\text { extras }\end{array}$ \\
\hline art. 134 & $\begin{array}{l}\text { Estabelece a possibilidade de parcelamento das férias em } \\
\text { três períodos. }\end{array}$ \\
\hline art. 396 & $\begin{array}{l}\text { Define que os horários de descanso da trabalhadora para } \\
\text { amamentação serão negociados com o empregador. }\end{array}$ \\
\hline art. 442 & $\begin{array}{l}\text { Institui que o trabalhador autônomo contratado com ou } \\
\text { sem exclusividade, de forma contínua ou não, não é em- } \\
\text { pregado da empresa }\end{array}$ \\
\hline \hline art. 611-§ A, in- \\
cisos I, II, III, \\
VIII, X, XI e \\
XIII & $\begin{array}{l}\text { Estabelece a prevalência do negociado sobre o legislado } \\
\text { sobre a jornada de trabalho, o banco de horas anual, o in- } \\
\text { tervalo intrajornada (mínimo de 30 minutos), o teletraba- } \\
\text { lho, o trabalho intermitente, o registro de jornada de tra- } \\
\text { balho, a troca do dia de feriado e a prorrogação de jorna- } \\
\text { da em ambientes insalubres, sem licença prévia das auto- } \\
\text { ridades competentes do Ministério do Trabalho. }\end{array}$ \\
\hline $\begin{array}{l}\text { Cria o trabalho intermitente, em que a prestação de servi- } \\
\text { ços, com subordinação, não é contínua, mas por horas, } \\
\text { podendo auferir salário inferior ao mínimo legal, incluin- } \\
\text { do o denominado "salário zero" ao final do mês, sem } \\
\text { cômputo do tempo de serviço à disposiça da emprega- }\end{array}$ \\
\hline dora.
\end{tabular}

Fonte: elaborado pela pesquisa a partir da lei 13467/2017 e da bibliografia consultada

Em direção análoga, os novos trabalhos digitais como o chamado teletrabalho (para o qual não serão empregadas as regras da CLT sobre jornada) e o trabalho em home office (que não tem previsão de pagamento de horas extraordi- 
nárias) engendram tempos de trabalho não pago e expropriam tempo de vida livre dos trabalhadores, sob a mística de exercício de maior liberdade na gestão do tempo. Isso, inclusive, no tocante ao trabalhador assalariado presencial que, ao se manter conectado ao trabalho por meio dos dispositivos digitais, prolonga a ocupação, borrando as fronteiras entre tempo de trabalho e tempo de não trabalho.

O assalto sobre o tempo dos trabalhadores tem no alargamento do limite das horas extras e no sistema de compensação de horas ${ }^{14}$ (banco de horas) uma forma de subtrair rendimentos dos trabalhadores, quando, por exemplo, trocam-se horas trabalhadas a mais por horas a serem dispensadas, encurtando a remuneração do trabalho necessário, consequentemente ampliando o sobretrabalho. ${ }^{15}$

Por outro lado, no trabalho intermitente, instituído como regime contratual em que o trabalhador fica à disposição da empresa, a remuneração se dá exclusivamente em função das horas efetivamente trabalhadas, podendo, inclusive, chegar no limite do chamado 'salário zero"' (LINS; SILVA, 2019, p. 482). Esse tipo de vínculo endossa os processos de precarização em sua totalidade e comporta formas variadas de apropriação de tempo de vida dos trabalhadores pelo capital, estruturando a incerteza de renda, a deterioração da saúde e a desorganização da vida da família proletária.

O contrato para trabalho intermitente é uma janela que se abre para o capital se desobrigar de certos custos com a reprodução da força de trabalho e isso potencializa o movimento da superpopulação relativa porque esses trabalhadores ganharão apenas pelo trabalho efetivamente realizado, ao mesmo tempo que se mantém vinculado à empresa (capacitado nas requisições da mesma) e, assim, facilmente acionável de acordo com as demandas imediatas. Então, a relação da superpopulação relativa com o exército ativo de trabalhadores empregados ganha novos contornos nessa quadra histórica, inclusive, porque a camada flutuante tem maior organicidade com o fluxo contínuo do capital.

A autorização da lei $13.467 / 2017$ para o alargamento da carga horária de trabalho, a variabilidade da jornada e a redução do intervalo para almoço na empresa e de descanso (dia, semana, ano) sugere que o seu desenrolar desafia a saúde dos trabalhadores. O descontrole da jornada nos diferentes contratos de trabalho aprofunda o avanço do tempo de trabalho sobre o tempo de vida do

\footnotetext{
${ }^{14}$ Esses mecanismos já existiam, conforme expresso no início dessa seção. A ênfase aqui é pelo fato de que a Reforma exponencia esse subterfúgio.

${ }^{15}$ Krein et al. (2019) certificam que a adoção do banco de horas se tornou muito presente nos setores mais estruturados da economia.
} 
trabalhador, aumentando os riscos à saúde pelo estresse físico e emocional, além do apuro de acidentes (DRUCK et al., 2019).

Vale acrescentar que a conjuntura de revisão da legislação do trabalho é adensada também pela alteração das normativas sobre a terceirização (externalização de processos de trabalho para empresas contratadas). Até 2017, a subcontratação de empresas era autorizada restritivamente pelo artigo 455 da CLT (subempreitada), pela lei 8987/1995 (regime de concessão e permissão), pela lei 9742/1997 (telecomunicações), pela lei 7102/1983 (vigilância bancária), pela lei 6019/1974 (trabalho temporário) e, principalmente, pela Súmula 331 do Tribunal Superior do Trabalho que autorizava a transferência a terceiros somente das atividades secundárias das empresas (atividades-meio), delimitando como ilícitas as externalizações das atividades-fins. A lei 13.429/ 2017 - que autoriza a subcontratação de qualquer atividade empresarial - e a lei 13.467/2017 alteram esse quadro, fortalecendo legalmente a pilhagem das relações de trabalho.

Por outro lado, o governo Jair Bolsonaro (2019-2022), eleito com forte campanha conservadora em favor da ampliação da flexibilização da legislação trabalhista, instituiu medida provisória de liberdade econômica em que, entre outros dispositivos, altera pontos da regulação do trabalho. Aprovada no Congresso Nacional, com restrições a algumas proposições do executivo, a lei 13.874/2019 modificou, fundamentalmente, a assinatura de ponto de entrada e saída do trabalho que passou a ser obrigatória somente para empresas com mais de 20 empregados, esfumaçando a efetiva jornada de trabalho e facilitando a indução de horas extraordinárias sem remuneração ou compensação. ${ }^{16}$ Posteriormente, ao fim do primeiro ano, o governo emitiu uma medida provisória, 905/2019, propondo variadas alterações na CLT e especificamente algumas delas voltadas para o primeiro emprego para jovens de 18 a 29 anos. A medida está em debate no Congresso Nacional e no Superior Tribunal de Justiça por questionamento de inconstitucionalidade. ${ }^{17}$

${ }^{16}$ Em novembro de 2019, por iniciativa do executivo, foi aprovada a reforma da previdência pela Emenda Constitucional 103/2019 que estabeleceu a regressão de benefícios previdenciários e ampliou os requisitos para aposentadoria por idade, alongando o tempo de atividade laborativa do trabalhador, além de ampliar o percentual de contribuição do trabalhador. Foge às nossas possibilidades no momento tratar do tema da previdência, mas é possível ver que, por mais de trinta anos, variados dispositivos foram alterados por diferentes governos. Como o tema se relaciona ao processo de reprodução da força de trabalho ativa e inativa, seria interessante rearticular o tema a esse núcleo da crítica da teoria do valor.

${ }^{17}$ Ainda que receba muitas críticas, sobretudo pela celeridade em encaminhar temas importantes por meio de medida provisória e não de projeto de lei, a proposição deixanos ver a disposição da composição política que personifica as demandas do capital 
A pilhagem de direitos e a oficialização legal da precarização, ocorrida com a lei 13467/2017, não ampliaram os empregos como prometido, pois o desemprego alto segue como um dos indicadores depressivos da economia (DRUCK, et al., 2019), por isso expressa a conjuntura de desmonte de regulações do emprego, ampliando a margem de desoneração do capital e de apropriação de tempo de trabalho excedente para recomposição da taxa média de lucro.

\section{Considerações Finais}

O desafio desse estudo foi o de elaborar uma reflexão-síntese da crítica da economia política sobre a reforma trabalhista de 2017, nesse espaço limitado, motivo porque o texto não aborda variáveis importantes como o papel do Estado e das organizações políticas. Optamos por centralizar a exposição nos fundamentos e na demonstração do sentido social das mudanças substantivas realizadas na CLT. Para isso, foi fundamental a hipótese centrada no tempo de trabalho como categoria vinculada a especificidade do mais valor na forma social capitalista. Assim é possível entender o dispositivo legal no contexto da gestão da força de trabalho para o capital, de modo que problematizamos as alterações normativas mostrando que está em questão um processo coetâneo mundial, a partir dos anos de 1970, por uma nova configuração do tempo de trabalho médio e esse tempo passa a referenciar a competição de capitais por mais-valor extraordinário. O que impulsiona a disputa política em torno das legislações do

na atualidade, exemplificando a reflexão que desenvolvemos aqui. Outrossim, sobre as questões do primeiro emprego vimos na pesquisa que a medida provisória propõe a contratação sem as garantias da CLT e sem convenção coletiva; a redução do percentual depositado no FGTS (Fundo de Garantia por Tempo de Serviço) de 8\% para 2\%; a redução da multa sobre o saldo do FGTS de 40\% para 20\% nos casos de demissão sem justa causa; o parcelamento das férias e do saldo do FGTS (em até 12 meses); a redução do adicional de periculosidade de $30 \%$ para $5 \%$; a isenção da contribuição previdenciária de $20 \%$ para os patrões; além de deixar de reconhecer como acidente de trabalho os acidentes ocorridos no trajeto para o trabalho ou para casa, perdendo, o jovem trabalhador, o direito ao auxílio-doença. Essa proposta nomeada pelo governo como "contrato verde e amarelo" para jovens desempregados é uma proposição de trabalho precário porque autoriza o rebaixamento do valor de troca da força de trabalho reeditando mais uma "lei sanguinária", com incidência sobre todo o quadro de regulação do trabalho no Brasil. Vale acrescentar que no início do governo o Ministério do Trabalho foi extinto depois de 88 anos de existência e as atribuições divididas entre o Ministério da Economia, Ministério da Cidadania e Ministério da Justiça e da Segurança Pública. 
trabalho, no sentido de garantir a ampliação do trabalho não pago da jornada, prolongando e intensificando a jornada, flexibilizando os contratos de emprego e reduzindo o descanso no local de trabalho. Essas táticas visam encurtar o gasto do capital com tempos não produtivos (os tempos porosos remunerados), com os salários (renda do trabalho necessário) e com o mais valor distribuído para a proteção social e os processos na justiça do trabalho. As mudanças envolvem também uma miríade de possibilidades de transferir para o trabalhador os custos da realização das atividades mediatas que viabilizam o trabalho em si. A lei estabelece novos parâmetros de gestão da força de trabalho, capturando mais tempo social dos trabalhadores e diminuindo custos produtivos que tem repercussão sobre o lucro empresarial.

De maneira geral, incide sobre o tempo livre do trabalhador e as consequências disso merecem ser objeto de estudos na nossa área no sentido de apreciar os desdobramentos sobre a renda salarial, a saúde e a sociabilidade dos trabalhadores, destacando as repercussões sobre a reprodução da família proletária, com o rebaixamento do valor da força de trabalho e a desorganização do tempo de vida social.

Evidentemente, a legislação como parte do complexo do Estado envolve a gestão da exploração da força de trabalho, pois na forma social capitalista o valor da força de trabalho é subconsiderado, na medida em que seu pagamento é referenciado em parte da jornada (trabalho necessário) e não na magnitude produzida no conjunto do tempo de trabalho vendido. E esta é a face oculta da legislação que regula o trabalho capitalista em qualquer época, e isso merece ser considerado no estudo crítico da mesma. Os direitos do trabalho que estão sendo expropriados decorreram de lutas políticas dos trabalhadores e de necessidades de regular a própria competição capitalista, mas são dinâmicas sistêmicas de reprodução ampliada, ainda que possam ser disputas e ganhos políticos pontuais para melhores condições de reprodução da força de trabalho.

\section{Referências}

ANTUNES, R. O privilégio da servidão: o novo proletariado de serviços na era digital. São Paulo: Boitempo, 2018.

BARBOSA, R.N. de C. Questão social, crise do capital e formação profissional: desafios ao Serviço Social na contemporaneidade. Revista Sociedade em Debate. Pelotas, v. 24, n. 2, p. 245-272, mai/ago 2018. 
BASSO, P. Tempos modernos, jornadas antigas: vidas de trabalho no início do século XXI. Campinas: Unicamp, 2018.

CAMPOS, A. Breve histórico das mudanças na regulação do trabalho no Brasil. Texto para discussão. Instituto de Pesquisa Econômica Aplicada. Brasília/ Rio de Janeiro: Ipea, 2015.

CARDOSO, A.C. Organização e intensificação do tempo de trabalho. Revista Sociedade e Estado. Brasília, v. 28, n. 2, p. 351-374, maio / ago. 2013.

COUTINHO, G. "Reforma" trabalhista de Temer retrocede ao século 19. Brasília: DIAP - Departamento Intersindical de Assessoria Parlamentar, 2017.

DAL ROSSO, S. Jornadas excessivas de trabalho. Revista Paranaense de Desenvolvimento. Curitiba, v. 34, n. 124, p. 73-91, jan. / jun., 2013.

O ardil da flexibilidade. São Paulo: Boitempo, 2017.

DRUCK, G. et al. A contrarreforma neoliberal e a terceirização: a precarização como regra. Cad. CRH. Salvador, v. 32, n. 86, p. 289-305, maio / ago., 2019.

GIBB, L. Tendência de despadronização da jornada de trabalho. Tese (Doutorado em Desenvolvimento Econômico). Campinas: IE-UNICAMP, 2017.

GRESPAN, J. O negativo do capital. São Paulo: Expressão Popular, 2012.

KREIN, J. O desmonte dos direitos, as novas configurações do trabalho e o esvaziamento da ação coletiva. Tempo Social. São Paulo, volume 30, número 1, p.77-104, jan. / abril, 2018.

et al. (Org.) Reforma trabalhista no Brasil: promessas e realidade.

Campinas, SP: Curt Nimuendajú, 2019.

LINS, V.; SILVA, A. As reformas trabalhistas no mundo: a flexibilização no tempo de trabalho e na remuneração como vetor de precarização. Cadernos do CEAS. Salvador/Recife, n. 248, p. 481-513, set. / dez., 2019.

MANDEL, E. Capitalismo tardio. São Paulo: Abril Cultural, 1982.

MARX, K. Capítulo VI Inédito de O Capital: resultados do processo de produção imediata. São Paulo: Moraes, s/d.

MARX, K. Contribuição à crítica da economia política. Lisboa: Martins Fontes, 1977. 
O Capital: crítica da economia política. Rio de Janeiro: Civilização Brasileira, 2008.

Grundisse: manuscritos econômicos de 1857-1858: esboços da crítica da economia política. São Paulo: Boitempo, 2011.

PASSOS, S.; LUPATINI, M. A contrarreforma trabalhista e a precarização das relações de trabalho no Brasil. Revista Katálysis. Florianópolis, v. 23, n. 1, p. 132-142, jan./ abril, 2020. 
